\title{
REGLAS Y PRINCIPIOS EN EL DERECHO DEL TRABAJO. UNA MIRADA DESDE EL DERECHO DEL TRABAJO CHILENO*
}

\author{
RULES AND PRINCIPLES IN LABOR LAW. \\ A LOOK FROM THE CHILEAN LABOR LAW \\ RÈGLES ET PRINCIPES DU DROIT DU TRAVAIL. \\ UN REGARD SUR LA LOI CHILIENNE DU TRAVAIL
}

Pedro IRURETA URIARTE**

\begin{abstract}
RESUMEN: La reflexión sobre los principios propios del derecho del trabajo tuvo un alto desarrollo hacia mediados del siglo XX, cuestión que trajo como consecuencia una inflación de principios, abriéndose paso no sólo los de carácter jurídico, sino incluso otros claramente económicos o metajurídicos. No obstante, el principio protector es el único y gran principio de la disciplina laboral, y se plantea como un mandato de optimización destinado a que algo sea realizado en la mayor medida posible. A partir del principio protector, han surgido una serie de reglas que, en rigor, no reúnen las características propias de un principio jurídico ya que no tienen un carácter indeterminado y la mayor parte de las veces no presentan una textura abierta. Estas reglas (también denominadas principios de aplicación) no son más que derivaciones del principio protector. Lo anterior no impide que, en el derecho del trabajo, en cuanto disciplina jurídica, se apliquen asimismo los principios generales del derecho, los cuales interactúan con las reglas particulares de esta disciplina.
\end{abstract}

Palabras clave: principios, reglas, derecho del trabajo.

* Recibido el 5 de mayo de 2020 y aceptado para publicación el 3 de septiembre de 2020.

** Abogado y licenciado en derecho por la Pontificia Universidad Católica de Chile. Doctor en derecho por la Universidad Complutense de Madrid. Profesor de Derecho del trabajo de la Facultad de Derecho de la Pontificia Universidad Católica de Chile. El presente trabajo se inscribe en el proyecto de investigación Fondecyt núm. 1170948, "Los principios propios del derecho del trabajo en el ordenamiento jurídico chileno", ejecutado por el autor en calidad de investigador responsable. 
ABSTRACT: The reflection on the principles of labor law had a high development towards the middle of the 20 th century, an issue that brought an inflation of principles, opening the way not only to those of legal nature, but also to others clearly economic or meta-legal. However, the protective principle is the only and great principle of labor law, and since its origins has been raised as an optimization mandate that orders that something be done to the greatest extent possible. From the protective principle, a series of rules have arisen that, strictly speaking, do not meet the characteristics of a legal principle since they do not have an indeterminate character and most of the time do not present an open texture. These rules are no more than derivations of the protective principle. The above does not prevent that, in labor law, as a legal discipline, the general principles of law are also applied, interacting with the particular rules of this discipline.

Keywords: Principles, Rules, Labor Law.

RÉSUMÉ: La réflexion sur les principes du droit du travail a connu un fort développement vers le milieu du XXe siècle, une question qui a entraîné une inflation des principes, faisant place non seulement à ceux de nature juridique, mais à d'autres clairement économiques ou métajurides. Cependant, le principe de protection est le seul et grand principe de la discipline du travail, et il est proposé comme un mandat d'optimisation conçu pour s'assurer que quelque chose soit réalisé autant que possible. Du principe de protection, une série de règles ont émergé qui, à proprement parler, ne répondent pas aux caractéristiques d'un principe juridique car elles n’ont pas un caractère indéterminé et la plupart du temps elles n'ont pas de texture ouverte. Ces règles (également appelées principes d'application) ne sont que des dérivations du principe de protection. Ce qui précède n'empêche pas qu'en droit du travail, en tant que discipline juridique, s'appliquent également les principes généraux du droit qui interagissent avec les règles particulières de cette discipline.

Mots clés: principes, règles, droit du travail. 
SUMARIO: I. Introducción. II. La discusión en torno a los principios del derecho del trabajo. III. La teleología del derecho del trabajo y el principio protector. IV. Conclusiones. V. Bibliografía.

\section{INTRODUCCIÓN}

T os principios y las reglas constituyen parte integrante de todo ordenamiento jurídico. ${ }^{1}$ Debido a ello, se tiende a separar la figura del principio de las demás normas que integran un sistema normativo como si los primeros tuviesen un alcance más general y trascendente; mientras que las reglas, por el contrario, tuvieran un ámbito cerrado y acotado cuyas propiedades conforman un conjunto finito. Esta distinción es posible encontrarla en toda disciplina jurídica que aspira a tener caracteres de pertenencia dentro de un determinado sistema.

La distinción entre reglas y principios también afecta el ámbito del derecho del trabajo. ${ }^{2}$ Si una regla es válida y por tanto aplicable al caso particular, entonces el juez laboral no requiere entrar en un proceso de ponderación. Simplemente, está obligado a aplicarla. No ocurre lo mismo con los principios, los cuales se encuentran enunciados en términos generales y bajo la lógica de que ellos cobijan tras de sí un mayor alcance justificativo. ${ }^{3}$

La discusión en torno a las reglas y principios propios del derecho del trabajo ha estado presente desde los inicios de esta disciplina. Con distinto énfasis, y en diversas etapas cronológicas, la individualización de específicos principios y reglas laborales, así como su contenido esencial, ha ocupado la atención preferente de la dogmática y la jurisprudencia. Permanentemente, sobre todo en el ámbito latinoamericano, este binomio de reglas y principios es invocado como si se tratara de figuras de comprensión homogénea, permitiendo justificar la orientación de ciertas reformas legales o bien decisiones de los tribunales.

No obstante, y más allá del interés que despiertan, lo cierto es que la reflexión sobre el alcance de los principios jurídico-laborales no se ha traducido necesariamente en estudios generales y uniformes sobre la identidad y natu-

1 Guastini, Riccardo, Interpretary argumentar, trad. de Silvina Álvarez Medina, Madrid, Centro de Estudios Políticos y Constitucionales, 2014, p. 183.

2 Jeammaud, Antoine, "Les príncipes dans le droit francais du travail", Droit Social, París, núms. 9-10, 1982, pp. 618 y ss.

3 Véase Atienza, Manuel, y Ruiz Manero, Juan, Las piezas del derecho, 4a. ed., Barcelona, Ariel, 2016, p. 45; Luzzati, Claudio, El principio de autoridad y la autoridad de los principios, trad. de Pau Luque Sánchez, Madrid, Marcial Pons, 2013, pp. 133 y ss. 
raleza de éstos. ${ }^{4}$ Ello ha traído como consecuencia que, en no pocos casos, la falta de un estudio particular sobre los principios propios del derecho del trabajo haya significado, en la práctica, que su análisis y reflexión se reduzca a meras invocaciones jurisprudenciales, o bien, a referencias doctrinarias genéricas que, dependiendo de los supuestos, permiten fundamentar la aceptación o rechazo de una argumentación. La falta de estudios más pormenorizados ha supuesto, también, una confusión sobre qué postulados tienen la calidad efectiva de principio jurídico (es decir, que en caso de eliminarse se alteraría toda la fundamentación del derecho del trabajo) y cuáles simplemente constituyen reglas. ${ }^{5}$ Lo anterior, por cierto, se plantea sin dejar de reconocer que, parte importante de las reglas no son más que postulados positivizados que establecen claros límites en cuanto a su aplicación. ${ }^{6}$

Desde luego, y en no pocas ocasiones, la doctrina laboral ha realizado importantes aportes que se vinculan con el impacto que tienen los principios en la construcción del ordenamiento laboral. ${ }^{7}$ Probablemente el caso más signi-

4 Véase Jeammaud, Antoine, "L'inexistence, en droit du travail, d'un príncipe pro operario", en Cruz, Jesús et al. (coords.), Los grandes debates actuales en el derecho del trabajo y la protección social. Estudios en recuerdo del profesor Dr. Manuel Ramón Alarcón Caracuel, Sevilla, Centro Andaluz de Relaciones Laborales, 2016, p. 86; Mercader, Jesús, Los principios de aplicación del derecho del trabajo, Valencia, Tirant lo Blanch, 2014, p. 52.

5 Véase Alarcón, Manuel Ramón, "La vigencia del principio pro operario", en Montoya, A. et al. (coords.), Cuestiones actuales de derecho del trabajo. Estudios ofrecidos por los catedráticos españoles de derecho del trabajo al profesor Manuel Alonso Olea, Madrid, Centro de Publicaciones, Ministerio de Trabajo y Seguridad Social, 1990, p. 861; Jeammaud, Antoine, ibidem, p. 85.

6 Aarnio, Aulis, "Reglas y principios en el razonamiento jurídico", Anuario da Facultade de Dereito da Universidade da Coruña, La Coruña, núm. 4, 2000, p. 595; y Atienza, Manuel y Ruiz, Juan, "Sobre principios y reglas", Doxa, Valencia, núm. 10, 1991, p. 106.

7 Dentro de la doctrina laboral chilena, cabe destacar, entre otros, los aportes de Gaete, Alfredo, Principios generales de derecho del trabajo, Santiago, Editorial Jurídica de Chile, 1951; Thayer, William, "Un punto de vista sobre los principios del derecho del trabajo", Revista Jurídica del Trabajo, Santiago, núm. 501, 1984; Walker, Francisco, "Algunas reflexiones de carácter doctrinario sobre los embates flexibilizadores de las relaciones laborales, los principios del derecho del trabajo, su razón de ser y su futuro", Temas Laborales, Santiago, año 7, 2002; id., "Principios orientadores del derecho del trabajo”, Revista Jurídica del Trabajo, Santiago, núm. 501, 1984; López Oneto, Marcos, El principio de protección a la fuente del empleo en Chile, Santiago, Thomson Reuters, 2013; Palomo, Rodrigo, "El rol de los principios en la aplicación del derecho del trabajo. Antecedentes conceptuales sobre el estado del arte en Chile", Revista Laboral Chilena, Santiago, núm. 11, 2007; $i d$., "Los principios del derecho del trabajo. Cuestiones de la teoría tradicional y planteamiento de nuevos problemas", Revista Laboral Chilena, Santiago, núm. 6 de 2006; Palavecino, Claudio, Los principios del derecho del trabajo, Santiago, Facultad de Derecho de la Universidad de Chile, Separata, 2008; Caamaño, Eduardo, "Análisis crítico sobre la aplicación de la doctrina de los actos propios en materia laboral", Revista de Derecho de la Pontificia Universidad Católica de Valparaíso, 
ficativo a nivel latinoamericano lo constituye la célebre obra de Américo Plá, cuya influencia resulta evidente dentro de la dogmática laboralista.

Sin embargo, en muchos de estos aportes doctrinarios - particularmente en el caso del derecho del trabajo chileno- se ha echado de menos una visión más general y unitaria de los principios, al objeto de contar con criterios básicos que permitan identificar aquellas directrices que resultan propias del derecho del trabajo, introduciendo de paso un orden al interior de esta disciplina jurídica. También ha faltado un análisis más pormenorizado de las reglas, al objeto de establecer su contenido esencial y así distinguirlas claramente de los principios propiamente tales.

Consideraciones similares podrían efectuarse en relación con la jurisprudencia. Si bien la labor de los tribunales ha permitido en variadas ocasiones reconocer e identificar a los principios propios del derecho del trabajo, ${ }^{8}$ esta construcción también se ha llevado a cabo de manera dispar, sin demasiados criterios sistematizadores y generando una serie de interrogantes sobre los límites de su aplicación. En muchos de estos casos, la invocación jurisprudencial de principios era el resultado de un razonamiento jurídico que presumía la existencia de estos postulados propios del orden laboral (ya fuesen implícitos o explícitos), utilizándolos como último recurso o inferencia deductiva que garantizaba la validez de la resolución del juzgador. ${ }^{9}$ Sólo durante los últimos 30 años de vigencia de normativa laboral en Chile, es posible observar un mayor interés de la jurisprudencia por estructurar una visión más compleja de los principios, sin que ello permita concluir que existe un cuerpo de doctrina judicial completo y amplio de esta temática. ${ }^{10}$

Valparaíso, núm. 32, 2009; Irureta, Pedro, "El impacto de los principios jurídicos en el derecho del trabajo", en Carbonell, F. et al. (coords.), Principios jurídicos. Análisis y crítica, Santiago, Legal Publishing, 2011; id., "La vigencia del principio de buena fe en el derecho del trabajo chileno", Ius et Praxis, Talca, año 17, núm. 2, 2011; Ugarte, José Luis, "La rehabilitación de los principios del derecho del trabajo y el concepto del derecho", Derecho Laboral, Montevideo, núm. 252, 2013.

8 De hecho, el artículo 459, núm. 5 del Código del Trabajo chileno dispone que la sentencia definitiva deberá contener los "preceptos constitucionales, legales o los contenidos en tratados internacionales... las consideraciones jurídicas y los principios de derecho o equidad en que el fallo se funde".

9 Desde una perspectiva general, relativa al carácter de los principios, véase Prieto, Luis, Apuntes de teoría del derecho, 10a. ed., Madrid, Trotta, 2016, p. 209; Esser, Jossef, Principio y norma en la elaboración jurisprudencial del derecho privado, Barcelona, Bosch, 1961, pp. 19 y ss.

10 Véase López Oneto, Marcos, Elprincipio de protección a la ... op. cit., pp. 53 y 54 . Y agrega en p. 105: "Existiendo un variado, complejo y numeroso repertorio de aplicaciones jurisprudenciales de estos (principios), en donde han sido utilizados directamente como normas decisoria 
Lo anterior contrasta, según se ha dicho, con la importancia que la cultura jurídico-laboral parece asignarles a estas figuras, y con el valor que los principios adquieren como instrumento de interpretación normativa y de resolución de casos. En este orden de ideas, la dogmática tiende a centrarse en aspectos más bien puntuales o casuísticos de los denominados principios clásicos del derecho del trabajo (relegando a un segundo plano el análisis de los elementos más generales y esenciales de cada uno de ellos); y la jurisprudencia no ha terminado de definir su aceptación por principios meramente explícitos o eventualmente por principios que aun cuando se encuentren privados de reglamentación o reconocimiento, de todas formas pueden ser extraídos de un criterio más vinculado al espíritu general de la legislación. ${ }^{11}$ A fin de cuentas, la jurisprudencia no delimita en todos los casos la concurrencia de principios explícitos o implícitos; y en el caso de estos últimos, se actúa como si todos los operadores del derecho tuvieran la misma noción jurídica de principio y un mismo entendimiento sobre su estructura. ${ }^{12} \mathrm{Y}$ por si lo anterior no fuese suficiente, en innumerables ocasiones tanto la doctrina como la jurisprudencia tienden a hablar de principios constitucionales, principios legales o principios jurisprudenciales, no tanto como principios jurídicos propiamente tales, sino como una manera de referirse a una fuente del derecho. ${ }^{13}$

A pesar de lo anterior, y aceptando que en el derecho del trabajo cada principio clásico tiene su propio contenido esencial (y la mayoría de las veces,

litis o como ratio decidendi, la ausencia de una explicación sistemática y dogmática de los mismos, es un notorio déficit teórico”.

11 Sobre la relación entre el "espíritu general de la legislación” y los "principios generales del derecho", véase Arce y Flores-Valdés, Joaquín, Los principios generales del derecho y la formulación constitucional, Madrid, Civitas, 1990, pp. 51 y ss., y Chandía, Sebastián, "Principios jurídicos y ordenamiento jurídico. Bases para una teoría general de los principios jurídicos en el sistema constitucional chileno", Derecho y Humanidades, Santiago, núm. 20, 2012, p. 206.

12 Véase, en relación con el derecho francés, pero aplicable a nuestro entorno, Jeammaud, "Les príncipes...", cit., p. 619. Desde una perspectiva más general, véase Guzmán, Alejandro, "La idea de "principio» mentada en la expresión "principios generales del derecho»", en Reinoso, F. (dir.), Principios generales del derecho. Antecedentes históricos y horizonte actual, Madrid, Thomson Reuters-Aranzadi, 2014, p. 1.

13 Aguiló, Josep, Teoría de las fuentes del derecho (y el orden jurídico), Barcelona, Ariel, 2012, p. 173; Beladíez, Margarita, Los principios jurídicos, 2a. ed., Madrid, Civitas, 2010, p. 134; Rojas, Víctor Manuel, Dworkin y los principios generales del derecho, México, Porrúa, 2007, pp. 12 y ss.; Leguina, Jesús, "Principios generales del derecho y Constitución”, Revista de Administración Pública, Madrid, núm. 114, 1987, p. 7; Arce y Flores-Valdés, Joaquín, Los principios generales..., cit., p. 93; Esser, Jossef, Principio y norma..., cit., pp. 169 y ss. 
su propio reconocimiento legal), ${ }^{14}$ en el orden laboral urge un análisis unitario que permita encontrar un hilo conductor en cada uno de ellos, que se caracteriza por la constatación de que estos principios no son más que postulados derivados de un axioma fundante de la disciplina laboral, como lo es el principio protector.

\section{LA DISCUSIÓN EN TORNO A LOS PRINCIPIOS}

\section{DEL DERECHO DEL TRABAJO}

$\mathrm{T}$ oda disciplina jurídica debe tener claridad sobre sus principios. Ello requiere de un importante nivel de reflexión capaz de resolver sus fronteras y distinguirlos de sus reglas. En el caso del derecho del trabajo, esta reflexión tuvo un alto desarrollo hacia mediados del siglo XX, lo cual era coincidente con el apogeo del sistema fordista de producción. ${ }^{15}$ Este apogeo, trajo como consecuencia una inflación de principios, abriéndose paso no sólo los de carácter jurídico, sino que otros claramente económicos o metajurídi$\cos (v . g r$., principio de la productividad o principio de la progresividad). Asimismo, la proliferación de principios se tradujo, en no pocos supuestos, en una reiteración con otro nombre de principios ya aceptados. ${ }^{16}$ Las funciones y grados de generalidad de estos principios eran variados, y hasta el día de hoy se pueden encontrar repartidos en el ámbito sustantivo de las condiciones de empleo y trabajo, en la interpretación y articulación de las fuentes de producción normativa, en el proceso laboral o, en fin, en las relaciones colectivas de trabajo. ${ }^{17}$

En el caso latinoamericano, el mayor desarrollo en estudiar y analizar dichos principios, se expresó en diversas monografías y tratados destacando en-

\footnotetext{
14 Prieto, Luis, Apuntes de..., cit., p. 208.

15 Irureta, Pedro, "El impacto"..., cit., p. 291.

16 Véase Podetti, H., "Los principios del derecho del trabajo", en De Buen, N. y Morgado, E. (coords.), de Instituciones de derecho del trabajo y de la seguridad social, México, Academia Iberoamericana de Derecho del Trabajo-UNAM, 1997, p. 1127; Vida, José et al., Manual de derecho del trabajo, 3a. ed., Granada, Comares, 2005, p. 37; Almansa, José Manuel, "Los principios generales del derecho ante la jurisprudencia constitucional laboral”, en Iglesia, J. L. (coord.), Estudios jurídicos en homenaje al profesor Aurelio Menéndez, Madrid, Civitas, 1996, t. IV, p. 4241; Rodríguez, Jorge, "Los principios del derecho del trabajo", en García, H. et al. (coords.), El derecho del trabajo en tiempos de cambio. En honor de Adrián Goldin, Buenos Aires, Ediar, 2017, p. 299; id., "Realismo y principios jurídicos en el derecho del trabajo", Derecho del Trabajo, Buenos Aires, año XLVIII, núm. 11, 1988, p. 1913; y Barbagelata, Héctor-Hugo, "Los principios de derecho del trabajo de segunda generación”, IUSlabor, núm. 1, 2008, pp. 7 y ss.

17 Martín, Antonio et al., Derecho del trabajo, 24a. ed., Madrid, Tecnos, 2015, p. 96.
} 
tre ellos la clásica obra de Américo Plá (Los principios del derecho del trabajo). ${ }^{18} \mathrm{Su}$ aporte fue tan relevante en esta materia, que tanto la doctrina como la jurisprudencia lo siguen invocando como una referencia obligada en la discusión de esta temática; y gran parte de las descripciones generales que se aplican en materia de principios propios del derecho del trabajo "giran en torno a la taxonomía y propuesta teórica que, en 1975, Américo Plá Rodríguez” planteó. ${ }^{19}$

Con todo, la reflexión actual de los principios, en el ámbito laboral, ha decaído. Se parte de la base que la mayoría de los denominados principios del derecho del trabajo tienen una regla legal específica (en torno a las cuáles se organiza una determinada regulación positiva) y que estas reglas permiten obtener mayor certeza jurídica (sin perjuicio de que en muchas de esas reglas se han terminado matizando los efectos de figuras que pretendían alzarse como verdaderos principios de esta disciplina).

El decaimiento en torno a la discusión de los principios laborales se ha visto amparado, además, por la relevancia que han adquirido los principios generales del derecho en el diseño normativo y jurisprudencial del derecho del trabajo (en cuanto rama del ordenamiento jurídico). ${ }^{20}$ Estos principios generales han convivido con reglas específicas (también denominadas principios de aplicación del derecho del trabajo), cuestión que ha terminado provocando que, en las últimas décadas, se haya puesto mayor énfasis en la exégesis de la normativa laboral (lo que ha ido de la mano de reformas puntuales y minuciosas), y no tanto en la reflexión de los principios propios. ${ }^{21}$

18 Plá, Américo, Los principios del derecho del trabajo, Buenos Aires, Ediciones Depalma, 1978.

19 Véase López Oneto, Marcos, El principio de protección..., cit., p. 99; Barbagelata, HéctorHugo, "Los principios de...", cit., pp. 3 y 4; Varios autores, Los principios del derecho del trabajo en el derecho peruano. Libro homenaje al profesor Américo Plá Rodríguez, Lima, Grijley, 2009; Varios autores, En torno a los principios del derecho del trabajo. Homenaje al Dr. Américo Plá Rodríguez, en Pasco Cosmópolis, Mario (coord.), México, Porrúa, 2009.

20 Véase, Lyon-Caen, Gérard, "Les príncipes généraux du droit du travail”, Téndances du droit du travail Français Contemporain. Études offertes à G. H. Camerlynck, París, Dalloz, 1978, p. 42; Deveali, Mario L., Tratado de derecho del trabajo, Buenos Aires, La Ley, 1964, t. I, p. 386; Vázquez, Antonio, Tratado de derecho del trabajo, Buenos Aires, Astrea, 1993, t. 2, p. 126; Montoya, Alfredo, "Principios y valores en el derecho del trabajo", en Pasco, Mario (coord.), En torno a los principios del derecho del trabajo. Homenaje al Dr. Américo Plá Rodríguez, cit., p. 19; González del Rey, Ignacio, "Principios generales", en García, J. (ed.), El sistema de fuentes de la relación laboral: estudios ofrecidos al profesor Martín Valverde por el Área de Derecho del Trabajo de la Universidad de Oviedo, Oviedo, Ediciones de la Universidad de Oviedo, 2007, p. 271.

21 Martín, Antonio, "Principios y reglas en el derecho del trabajo. Planteamiento teórico y algunos ejemplos", en Villa Gil, L. E. de la, y López, L. (dirs.), Los principios del derecho del trabajo, Madrid, Centro de Estudios Financieros, 2003, p. 67; Cruz, Jesús, "Los principios informado- 
La disgregación argumentativa en torno a los principios no ha podido borrar, en todo caso, un hecho evidente: en la base fundacional del derecho del trabajo se encuentra el principio protector. Ahí está su origen y su razón de ser, y lo cierto es que la mayor parte de sus reglas, o los denominados principios clásicos o de aplicación del derecho del trabajo, no son más que derivaciones de este primer gran principio, el cual en muchos ordenamientos latinoamericanos encuentra reconocimiento en la propia Constitución. ${ }^{22}$ Teniendo presente que los conflictos de la vida social se regulan a través de reglas y no de principios, aquéllas fueron las encargadas de juridificar (Verrechtlichung) el conflicto derivado del desequilibrio estructural tan propio de la sociedad industrial, asumiendo el mandato que les entregaba su principio fundacional. La incorporación de estas reglas particulares se ha intentado explicar, además, en la prevalencia que adquiere para la disciplina laboral una idea de justicia solidarista que subsana las deficiencias de los principios individualistas. ${ }^{23}$

\section{LA TELEOLOGÍA DEL DERECHO DEL TRABAJO \\ Y EL PRINCIPIO PROTECTOR}

\section{L}

a reflexión sobre los principios del derecho del trabajo se estructura en torno a la finalidad esencialmente tuitiva y correctora de derechos que

res del ordenamiento laboral", en Fargas, J. (coord.), Los derechos laborales desde la perspectiva de la teoría general del contrato y de la normativa internacional, Barcelona, Huygens, 2016, p. 187.

22 Sobre referencias al principio protector en cartas fundamentales de nuestro entorno, véase, por ejemplo, el artículo 7o. de la Constitución uruguaya de 1997; el artículo 25 de la Constitución de Colombia de 1991, o el artículo 7o. de la Constitución de Brasil de 1988. Una de las primeras manifestaciones de este reconocimiento puede encontrarse en el artículo 123, párrafo XXVII, de la Constitución mexicana de 1917, el cual grafica el carácter protector que se le asigna a la disciplina laboral: "Serán condiciones nulas y no obligarán a los contrayentes, aunque se expresen en el contrato: h) Todas las demás estipulaciones que impliquen renuncia de algún derecho consagrado a favor del obrero en las leyes de protección y auxilio a los trabajadores". Un criterio similar siguió el artículo 7o. de la Constitución de Weimar (Alemania) de 1919: "El Imperio puede legislar sobre las materias siguientes: 9o. Derecho obrero, seguro y protección de trabajadores y empleados y colocación de éstos"; y en su artículo 153 agregó: "El trabajo está colocado bajo la protección particular del Estado".

23 Almansa, José Manuel, "Los principios...”, cit., pp. 4238 y 4239; Rodríguez, Jorge, "Los principios...", cit., p. 301; cfr., Villa, Luis Enrique de la, "Rasgos, caracteres y principios del derecho del trabajo", en Palomeque, M. C. y García-Perrote, I. (dirs.), Derecho del trabajo y seguridad social: cincuenta estudios del profesor Luis Enrique de la Villa Gil: Homenaje a sus 50 años de dedicación universitaria, Madrid, Centro de Estudios Financieros, 2006, p. 344. 
en esencia constituye esta disciplina. ${ }^{24}$ Desde sus orígenes, estas exigencias de protección del trabajador permitieron justificar la autonomía de esta rama del ordenamiento jurídico y diferenciarla del derecho común. Ello explica, en parte, la circunstancia de que muchas Constituciones hayan recogido al principio protector dentro de sus normas. ${ }^{25}$

Esa protección declarada en los textos constitucionales llevó a reconocer la preeminencia del trabajo como principio ordenador del sistema jurídico, consiguiendo que éste se constituyera como la base material de la sociedad en torno a la cual se organizan las relaciones sociales y los conflictos propios del sistema productivo. ${ }^{26}$ Desde esta perspectiva, el principio protector se configura como un tipo de estándar, ${ }^{27}$ más elástico y flexible, que propone un objetivo que ha de ser alcanzado y que le termina otorgando identidad a la disciplina; o si se quiere, permite otorgarle un carácter más prescriptivo como si en la especie existiera un mandato de optimización que ordena que algo sea realizado en la mayor medida posible, dentro de las posibilidades jurídicas y reales existentes. ${ }^{28}$

La finalidad protectora se plasma, además, de un modo más formal, en el reconocimiento de la dignidad de la persona del trabajador y que se conecta

24 Bonnechère, Michèle, "Sur l'ordre public en droit du travail: les príncipes sont toujourd là...", Le Droit Ourrier, París, núm. 714, 2008, p. 12; Bocquillon, Fabrice, "Que reste-t-il du «principe de faveur»?”, Droit Social, París, núm. 3, 2001, pp. 255 y ss.; Thayer, William y Novoa, Patricio, Manual de derecho del trabajo, 3a. ed., Santiago, Editorial Jurídica de Chile, 1998, t. II, p. 28; Montoya, Alfredo, Derecho del trabajo, 29a. ed., Madrid, Tecnos, 2008, p. 219.

25 Montoya, Alfredo, "La aplicación del derecho del trabajo y el sistema de principios, valores y derechos fundamentales", Revista del Ministerio de Trabajo e Inmigración, Madrid, núm. 88, 2010, pp. 16 y ss.; para el caso chileno, véase Irureta, Pedro, Constitución y orden público laboral. Un análisis del artículo 19 N $^{\circ} 16$ de la Constitución chilena, Santiago, Facultad de Derecho de la Universidad Alberto Hurtado, Colección de Investigaciones Jurídicas, núm. 9, 2006, p. 52.

26 Irureta, Pedro, Constitución..., cit., p. 53.

27 Dworkin, Ronald, Los derechos en serio, trad. de Martha Gustavino, Barcelona, Ariel, 1999, pp. 72 y ss.

28 Véase Alexy, Robert, Teoría de los derechos fundamentales, trad. de Carlos Bernal Pulido, Madrid, Centro de Estudios Políticos y Constitucionales, 2017: "los principios son normas que ordenan que algo sea realizado en la mayor medida posible, dentro de las posibilidades jurídicas y reales existentes", y agrega: "los principios son mandatos de optimización, que se caracterizan porque pueden cumplirse en diferente grado y que la medida debida de su cumplimiento no sólo depende de las posibilidades reales sino también de las jurídicas”, pp. 67 y 68; id., La construcción de los derechos fundamentales, Buenos Aires, Ad-Hoc, 2010: "Las reglas son entonces normas que sólo pueden ser cumplidas o no. Por el contrario, los principios son normas que algo sea realizado en la mayor medida posible", p. 20. 
con la exigencia de condiciones laborales justas. ${ }^{29}$ Eso ocurre, por ejemplo, en el caso chileno cuando el artículo 2o. del Código del Trabajo explicita que "las relaciones laborales deberán siempre fundarse en un trato compatible con la dignidad de la persona", ${ }^{30}$ o en la declaración que hace el mismo precepto en el sentido que "son contrarios a los principios de las leyes laborales, los actos de discriminación”; o el artículo 153 del mismo Código cuando se exige que el Reglamento Interno estipule "las normas que se deben observar para garantizar un ambiente laboral digno y de mutuo respeto entre los trabajadores"; o en fin, en el artículo 1o., letra c), del Decreto con Fuerza de Ley núm. 2, de 1967 (Ley Orgánica de la Dirección del Trabajo), en cuya virtud se le asigna al organismo fiscalizador la función de "divulgar los principios técnicos y sociales de la legislación laboral". Este tipo de referencias son usuales en los textos laborales comparados y reflejan el interés de consagrar un principio o una exigencia de tutela con respecto al trabajo humano.

Congruente con lo anterior, en la mayoría de los casos, el principio protector está estructurado en términos abiertos ya que mediante su invocación no se pretende enumerar exhaustivamente los hechos en presencia de los cuales se produce una determinada consecuencia. ${ }^{31}$ Más aún, debido a su carácter de principio, admite excepciones no formuladas (cuestión que, desde luego, no se verifica en el caso de las reglas). Asimismo, el principio protector es posible estructurarlo como una típica norma genérica que requiere de la formulación de otras normas y que puede ser ejecutada de modos distintos y alternativos. ${ }^{32}$

29 Almansa, José Manuel, "Los principios...”, cit., p. 4237; González, Jesús, La dignidad de la persona, 3a. ed., Pamplona, Civitas-Thomson Reuters, 2017, p. 251; Lastra, José Manuel, "Principios ordenadores de las relaciones de trabajo", Revista Española de Derecho del Trabajo, Madrid, núm. 104, 2001, p. 165; Pacheco, Luz, La dignidad humana en el derecho del trabajo, Madrid, Thomson-Civitas, 2007, pp. 32 y ss.; para una perspectiva más general, Becchi, Paolo, El principio de la dignidad humana, México, Fontamara, 2016, pp. 11 y ss.; Hoerster, Norbert, En defensa del positivismo jurídico, trad. de Ernesto Garzón Valdés, Barcelona, Gedisa, 2000, pp. 91 y ss.

30 Habrá que reconocer, en todo caso, que se trata de normas que han sido reguladas en parte como principio y en parte como regla. Alexy, Robert, Teoría de los..., cit., p. 87.

31 Guastini, Riccardo, Interpretar y argumentar..., cit., p. 187; véase Jeammaud, Antoine, "Le príncipe de faveur. Enquête sur une règle emergente”, Droit Social, París, núm. 2, 1999, pp. 115 y ss.

32 Guastini, Riccardo, Interpretar y ..., cit., p. 189. Y el mismo autor agrega: "O incluso: tomemos una norma constitucional que confiera un «derecho social», como el derecho al trabajo o el derecho a la salud; se trata de una norma programática o teleológica que recomienda al legislador el cumplimiento de un cierto fin; pues bien, una norma de este tipo exige otras normas (legislativas) que concreten el derecho conferido, pero, por otra parte, evidentemente, el derecho en cuestión puede ser concretado de muchos modos distintos”, p. 190. 


\section{La función esencialmente informadora del principio protector}

El principio protector, que se alza como una especie de telón de fondo de esta disciplina, tiene —en tanto principio jurídico- una función esencialmente informadora (cuestión que en el derecho del trabajo ha cobrado especial importancia). ${ }^{33}$ Dicha función permite dotar de sentido y sistematizar el ordenamiento jurídico laboral, dándole racionalidad y valor a las formulaciones jurídico-técnicas ${ }^{34}$ (aspecto especialmente relevante para orientar la acción del legislador). ${ }^{35}$ Esto evita que el derecho del trabajo sea concebido como una estructura neutra o de mera geometría social, cuestión que en la práctica le termina exigiendo una conexión con el sistema de valores. ${ }^{36}$

No obstante, terminada la etapa inicial del derecho del trabajo (y enfilado en una clara voluntad de ser reconocido como una disciplina jurídica con reglas, normas e instituciones), el principio protector comienza a buscar su exacta aplicación dentro del entramado legal: acepta que no tiene por objeto invertir la desigualdad o convertirse en un principio antiempleador; que no es un principio de filantropía legislativa; que no es un conjunto normativo de protección unilateral de intereses; que debe dejar espacio a la autotutela colectiva, y que debe tener presente las exigencias pro empleo (sobre todo en lo que respecta a las rigideces institucionales) tan propias de un ordenamiento que ha dejado de ser unilateral. $^{37}$

En este orden de ideas - y manteniendo su función informadora- el principio protector ha adquirido una rica y eficiente dimensión interpretativa. Esta dimensión no es exclusiva ni menos excluyente de otras reglas de interpretación; pero de todas formas ha logrado estructurarse como un mecanismo de ultima ratio, apto para clarificar la aplicación de normas de igual jerarquía (pero con distintos sentidos), y siempre que esta duda no haya podido ser superada por otras vías. ${ }^{38}$ Más aún: el principio protector no puede ser

33 Almansa, José Manuel, "Los principios...”, cit., p. 4235; Cruz, Jesús, "Los principios informadores...”, cit., p. 197.

34 Atienza, Manuel, y Ruiz Manero, Juan, Las piezas del..., cit., p. 44.

35 Ramos, José Antonio, "El fundamento del valor jurídico de los principios. Dworkin frente a Esser", Anuario de Filosofía del Derecho, Madrid, 1992, t. IX, p. 272.

36 Véase Conde, Emilia, La buena fe en el contrato de trabajo, Madrid, La Ley, 2007, p. 59.

37 Martín, Antonio, "Principios y reglas...", cit., p. 68; Cruz, Jesús, "Los principios...", op. cit., p. 209; Irureta, Pedro, "El impacto de...", cit., p. 299; Almansa, José Manuel, "Los principios...", cit., p. 4240.

38 Irureta, Pedro, "El impacto de los...”, cit., p. 300. 
invocado cuando el objetivo consiste en calificar hechos, ${ }^{39} \mathrm{o}$ para interpretar contratos ${ }^{40} \mathrm{O}$ bien para alterar la carga de la prueba. ${ }^{41}$ Tampoco ha resultado admisible su invocación cuando la norma es clara o unívoca, cuando existe ausencia de normas, ni menos para contrariar la voluntad del legislador. Por último, no es posible invocar el principio cuando la duda interpretativa puede resolverse acudiendo a otros criterios interpretativos. ${ }^{42}$ Como se ve, la dimensión hermenéutica ha ido encuadrándose bajo reglas específicas que delimitan su accionar.

Lo expuesto permite concluir que el principio protector se despliega en dos ámbitos claramente distintivos. En primer lugar, constituye un mandato de optimización que está en la base de la disciplina laboral. Dicho mandato ordena que la aspiración tutelar y correctora del desequilibrio estructural de las relaciones laborales sea realizado en la mayor medida posible. Ello permite infundirles sentido y valor a las formulaciones jurídico-técnicas, con objeto de que la normativa resultante sea congruente con el sistema de valores. Paralelamente, y superada la etapa de instalación de la disciplina, el principio en comento se ha venido alzando también como una típica regla de hermenéutica.

\section{Las reglas derivadas del principio general (también denominadas principios clásicos o de aplicación)}

A partir de la protección genérica del trabajo como elemento esencial de esta disciplina, el ordenamiento laboral se ha ido construyendo con base en reglas positivizadas que le otorgan especificidad (y que suelen agruparse terminológicamente en la noción de principios clásicos o principios de aplicación). ${ }^{43} \mathrm{La}$ aparición de estas reglas se encuentra íntimamente vinculada a la autonomía y especialización que evolutivamente fue adquiriendo el derecho del trabajo en

39 Ackerman, Mario, "El principio protectorio o de protección”, en Pasco, Mario (coord.), En torno a los principios del derecho del trabajo. Homenaje al Dr. Américo Plá Rodríguez, cit., p. 61.

40 Gárate, Javier, "El principio in dubio pro operario", Revista de Política Social, Madrid, núm. 135,1982 , p. 85.

41 Sagardoy, Juan Antonio, Los principios de aplicación del derecho del trabajo, 2a. ed., Madrid, Acarl, 1991, p. 24.

42 Desdentado, Aurelio, "El principio pro operario", en Villa, L. E. de la, y López Cumbre, L. (dirs.), Los principios del derecho del trabajo, Madrid, Centro de Estudios Financieros, 2003, p. 75; véase Cruz, Jesús, "Los principios...”, cit., p. 207.

43 Mercader, Jesús, Los principios de..., cit., p. 26. 
tanto disciplina jurídica, ${ }^{44}$ y que le permiten presentarse como una rama del ordenamiento jurídico que ostenta normas, principios, valores e instituciones distintivas.

En el ámbito laboral, las reglas positivizadas se estructuran en términos rigurosamente jurídicos y derivan precisamente del principio fundante de la disciplina. ${ }^{45}$ En efecto, a partir del carácter tuitivo del derecho del trabajo, comienzan a construirse criterios de interpretación o simples reglas legalmente establecidas, a las cuales la dogmática y la propia jurisprudencia comenzaron a denominar principios propios del orden laboral. ${ }^{46}$ Son reglas o principios de aplicación que se han desplegado en un contexto de protección individual o colectivo, aun cuando habrá que reconocer que en muchos ordenamientos ha existido un despliegue de reglas más intenso en las relaciones individuales y más bajo en las de orden colectivo. ${ }^{47}$

Por cierto, estas reglas presentan una serie de desafíos que ha debido resolver fundamentalmente la jurisprudencia: la tensión entre principio general y regla particular; la tensión entre principio general inmanente y regla específica, así como la configuración y los límites de cada regla. Asimismo, estas reglas han permitido efectuar una distinción entre principios tradicionales y principios emergentes del derecho del trabajo. ${ }^{48}$

Lo anterior obliga a concluir que los principios clásicos de la disciplina no son más que postulados estrictamente jurídicos, que no pretenden ser superiores ni ajenos al derecho, ni tampoco alzarse como una especie de principios supra jurídicos que impongan un determinado deber ser. ${ }^{49}$ Estos postulados dependen del diseño que el legislador les ha otorgado, aun cuando en la práctica sólo recojan parcialmente el principio fundante del derecho del trabajo. Y parte de las dificultades que se producen en su configuración radica precisamente en el hecho de que se trata de calificar como principios "a reglas

44 Cruz, Jesús., "La investigación en el derecho del trabajo", Lineamientos metodológicos para la investigación jurídica, Lima, núm. 2 de 2016, p. 22.

45 Javillier, Jean-Claude, Derecho del trabajo, Montevideo, Fundación de Cultura Universitaria, 2007, p. 92; Martín, Antonio, "Principios y...", cit., p. 67.

46 Véase Mercader, Jesús, Los principios de..., cit., p. 37.

47 Rodríguez-Piñero, Miguel, "Flexibilidad, juridificación y desregulación”, Relaciones Laborales, Madrid, 1987, t. I, p. 27.

48 Martín, Antonio, "Principios y reglas...", cit., pp. 57 y 70.

49 Montoya, Alfredo, "Principios y...", cit., p. 20. 
o instrumentos de diferente importancia y función", ${ }^{50}$ algunas de las cuales incluso tienen aplicación en otras parcelas del sistema jurídico. ${ }^{51}$

En el ordenamiento chileno, el Código del Trabajo ha recogido dentro de su estructura clásica —y de manera directa — una serie de reglas o principios de aplicación (aun cuando no se refiere a éstos como una especial fuente de la relación laboral). ${ }^{52}$ En algunos de estos casos, las reglas se comportan como simples criterios normativos del ordenamiento laboral destinados a actuar en ámbitos más bien limitados. Por ejemplo, el artículo 2o., incisos cuarto y siguientes, consagra el denominado principio de no discriminación laboral (que a su vez tiene respaldo en la propia Constitución); el artículo 4o., inciso segundo, y 159 núm. 4, incorporan el principio de continuidad de la relación laboral; el artículo 5o. se hace cargo del principio de irrenunciabilidad de los derechos laborales; el artículo 8o., junto a otras normas dispersas, recoge el principio de primacía de la realidad; y el artículo 62 bis regula la obligación del empleador en orden a dar cumplimiento al denominado principio de igualdad de remuneraciones entre hombres y mujeres que presten un mismo trabajo. En otros casos, se suman una serie de preceptos genéricos que de cierto modo reflejan la incorporación de principios como el de estabilidad en el empleo (en tanto manifestación privilegiada del principio de conservación del negocio jurídico), ${ }^{53}$ razonabilidad, buena fe contractual, y libertad sindical (que también tiene respaldo constitucional). ${ }^{54}$ Incluso, el mismo Código ha

50 Véase Ackerman, Mario, "El principio protectorio...,", cit., p. 27.

51 Ello ocurre, por ejemplo, con el denominado principio de primacia de la realidad. Aceptando la singularidad que este postulado adquiere en el ámbito laboral, lo cierto es que el propio derecho común consagra reglas de interpretación de los actos jurídicos fundadas en la ejecución práctica que las partes realizan sobre las estipulaciones contractuales.

52 Véase en relación con el ordenamiento uruguayo, pero aplicable al entorno latinoamericano, Plá Rodríguez, Alfredo, "Los principios del derecho del trabajo ¿constituyen una fuente del derecho?", Treinta y seis estudios sobre las fuentes del derecho del trabajo, Montevideo, Fundación de Cultura Universitaria, 1995, p. 9.

53 Sobre el particular, y a nivel doctrinario, véase Heredia, Ignasi, La estabilidad en el empleo: un concepto al margen de la duración temporal o indefinida del contrato, Pamplona, Aranzadi-Thomson Reuters, 2011, p. 111.

54 Para algunos, las reglas de proteccionismo colectivo han dado origen también al denominado principio de autonomía colectiva, en cuya virtud las "instituciones jurídico-laborales se orientan hacia un fomento de la solidifcación de la defensa y tutela de tales intereses colectivos, de la consolidación de las organizaciones de representación social de tales intereses, de la implantación de los medios de acción y negociación típicos de tales representaciones. En ocasiones, puede verse en ello un resultado más del carácter tuitivo propio del ordenamiento laboral". Cruz, Jesús, Compendio de derecho del trabajo, 11a. ed., Madrid, Tecnos, 2018, pp. 65 y 66. 
positivizado lo que denomina principios formativos del proceso laboral, entre los cuales destacan el de inmediación, impulso procesal de oficio, celeridad, buena fe, bilateralidad de la audiencia y gratuidad (artículo 425).

Pero, coetáneamente, se han venido incorporando en los ordenamientos un conjunto de principios laborales emergentes que, incursionando más allá de los principios clásicos, han podido ser extraídos de la propia legislación. Así ocurre, por ejemplo, con el principio de representación proporcional de los sindicatos, los principios de organización del trabajo y de prevención de la salud y seguridad de los trabajadores, o los principios que procuran la compatibilidad del trabajo con otros intereses del trabajador jurídicamente protegidos. ${ }^{55}$

\section{Las reglas o principios de aplicación del derecho del trabajo no tienen el carácter propiamente de principio jurídico}

Para hablar propiamente de un principio jurídico se requieren, a lo menos, dos requisitos: i) tener un carácter fundamental, y ii) estar sujeto a una peculiar forma de indeterminación. ${ }^{56} \mathrm{El}$ carácter fundamental pone el acento en la justificación axiológica de una multiplicidad de normas y, por tanto, no requiere de una confirmación ético-política toda vez que se les concibe como normas de por sí justas o correctas. ${ }^{57}$

El reconocimiento de un principio se adquiere básicamente mediante una positivización cuyo respaldo se encuentra en la propia normativa legal o en la acción de la jurisprudencia. No obstante, habrá que reconocer que la existencia del principio no puede ser reducida a una mera positivización, toda vez que resultaría un contrasentido pretender que el legislador explicite la totalidad de los supuestos en los cuales se funda un principio jurídico (que, al estar positivizado en la ley, adquieren la eficacia normativa de la norma respectiva)..$^{58}$ Por otra parte, la función de la jurisprudencia no es la de crear derecho, sino aplicarlo. ${ }^{59}$

\footnotetext{
55 Martín, Antonio, "Principios y reglas...", cit., pp. 69 y 70.

56 Véase Guastini, Riccardo, Interpretar..., cit., p. 184.

57 Ibidem, p. 186; Barros, Enrique, "Reglas y principios en el derecho", Anuario de Filosofía Jurídica y Social, Santiago, núm. 2, 1984, pp. 269 y ss.

58 Véase Beladíez, Margarita, Los principios..., cit., pp. 190 y 191: “... estos «principios del derecho positivo» no son en sentido estricto principios jurídicos. Son sólo las ideas en torno a las cuales se organiza una determinada regulación positiva".
}

59 Ibidem, p. 109. 
El que un principio tenga una peculiar forma de indeterminación, deja al descubierto una naturaleza de textura abierta o bien una configuración de normas derrotables o genéricas. ${ }^{60} \mathrm{El}$ problema es que la expresión principio jurídico es de carácter plurívoco, y en la práctica dicha formulación lingüística permite hacer referencia a un sinnúmero de alternativas. ${ }^{61}$ Como se ha señalado doctrinariamente, cuando se habla de principios se suele hacer mención de normas axiológicamente fundamentales, a normas generales o que inspiran amplios sectores del ordenamiento. ${ }^{62}$ También se habla de principios cuando se quiere hacer referencia a los fines de la acción estatal, a tópicos interpretativos o incluso para representar indeterminadamente el supuesto de hecho de su aplicación. ${ }^{63}$

Las reglas, por el contrario, tienen una dimensión distinta. ${ }^{64}$ Se trata de normas con un menor nivel de generalidad y que cualitativamente se diferen-

60 Véase Guastini, Riccardo, Interpretar..., cit., p. 187; véase Bäcker, C., "Reglas, principio y derrotabilidad", trad. de Francisco J. Campos Zamora, Doxa, Valencia, núm. 37, 2014, pp. 31 y ss.

61 Aarnio, Aulis, "Reglas y principios...", cit., p. 595; Pérez, Antonio-Enrique, "Los principios generales del derecho: ¿un mito jurídico?”, Revista de Estudios Políticos, Madrid, núm. 98, 1997, pp. 16 y ss.; véase a mayor abundamiento, Jeammaud, Antoine, "L'inexistence, en droit...", cit., p. 85, quien resalta el hecho de que, en el lenguaje de los juristas, el empleo de expresiones como "principio", "principio general" o "principio fundamental", está en expansión y se ha vuelto incontrolable, agregando que estos términos sufren de una "polisemia mal controlada"; Beladíez, Margarita, Los principios..., cit., p. 179: "Una vez se habla de «principio jurídico», otras de «principios del derecho», y también, como no, se ha acudido a la expresión... «principios generales del derecho»... en mi opinión, todas estas expresiones designan el mismo fenómeno".

62 Véase Prieto, Luis, Ley, principios, derechos, Madrid, Dykinson, 1998, p. 149; Guastini, Riccardo, Interpretar..., cit., p. 184: “....se consideran principios aquellas normas que incorporan tales valores, sentimientos de justicia, decisiones políticas”.

63 Véase Villa, Luis Enrique de la, "El principio de adecuación social y los conceptos jurídicos indeterminados en el derecho del trabajo", en Palomeque, M. C. et al. (coord.), Derecho del trabajo y seguridad social: cincuenta estudios del profesor Luis Enrique De la Villa Gil: Homenaje a sus 50 años de dedicación universitaria, Madrid, Centro de Estudios Financieros, 2006, p. 404.

64 El debate sobre sobre reglas y principios tiene un especial hito de relevancia en el conocido artículo de Ronald Dworkin publicado en University of Chicago Law Review y que tuvo por título "El modelo de las reglas" (1967). Con anterioridad a dicho estudio, que posteriormente fue incorporado en su célebre libro Los derechos en serio, el debate en torno a los principios se centraba fundamentalmente en las visiones iusnaturalistas y positivistas. No obstante, Dworkin supera esa lógica y plantea que las reglas son aplicables a la manera del todo o nada; es decir, si se dan los hechos que estipula la regla, entonces dicha directriz debe ser aplicada. Por el contrario, los "principios tienen una característica de la cual carecen las reglas: la dimensión de peso o importancia”. Dworkin, Ronald, Los derechos en serio, cit., p. 77. Según él, los principios 
cian de los principios. En efecto, las reglas permiten hacer aquello que exactamente se exige toda vez que contienen determinaciones en el ámbito de lo fáctico y jurídicamente posible. ${ }^{65} \mathrm{~A}$ diferencia de los principios, los conflictos de reglas se solucionan mediante cláusulas de excepción, o bien mediante criterios que permiten resolver las antinomias. Dentro de estos criterios destacan las metarreglas de lex superior, lexposterior y lex specialis. ${ }^{66}$

La lex superiorinvoca el criterio jerárquico según el cual en un conflicto entre reglas prevalece la norma de rango superior (lex superior derogat legi inferior).${ }^{67} \mathrm{Si}$ bien es cierto que este criterio constituye una consecuencia lógica de la pirámide de Kelsen, en el ámbito laboral tiene plena aplicación. La lex posterior por su parte, invoca el criterio cronológico, que impone la norma de más reciente data (lex posterior derogat legi priori). La lex specialis, por último, permite concluir que la ley especial prevalece sobre la general (lex specialis derogat generah). Este último criterio de la especialidad ha sido recogido en el artículo 13 del Código Civil chileno cuando se señala que las "disposiciones de una ley, relativas a cosas o negocios particulares, prevalecerán sobre las disposiciones generales de la misma ley, cuando entre las unas y las otras hubiere oposición"; en cierta

establecen consecuencias jurídicas que no se derivan automáticamente cuando se verifican los supuestos de hecho previstos en los mismos "pues pueden existir otros principios en sentido estricto o principios-directriz distintos que apunten en dirección contraria... y que hagan que el primero no prevalezca... en ese supuesto, y, por ello, no se aplique, dependiendo su aplicación del peso o importancia relativa de ellos... en el caso concreto planteado", véase Tardío, J. A., Los principios generales del derecho, Barcelona, Bosch, 2011, p. 58. Su reflexión también alcanzó al concepto de discreción en sentido fuerte y en sentido débil: si el derecho es un sistema de reglas, entonces el juez está obligado a aplicar o no las reglas a la manera del todo o nada. Por el contrario, si el sistema jurídico no sólo es un entramado de normas, sino que, además, de principios, entonces el juez se encuentra frente a estándares preexistentes que requieren de su discernimiento en lo que respecta a su aplicación. A partir de Dworkin, el debate sobre principios y reglas fue monopolizado fundamentalmente por la teoría del derecho, y desde luego los laboralistas poco aportaron en dicho debate que sentían ajeno a las particularidades de la disciplina.

65 Alexy, Robert, Teoría de los..., cit., pp. 67 y 68.

66 Sobre el particular, véase Ruiz, Juan, "Sistema jurídico: lagunas y antinomias", en González, D. (coord.), Conceptos básicos del derecho, Madrid, Marcial Pons, 2015, p. 60; Guastini, Riccardo, Las fuentes del derecho. Fundamentos teóricos, trad. de César E. Moreno More, Lima, Legales Ediciones, 2017, pp. 531 y ss. En el ámbito de la doctrina laboral, Martín, Antonio, "Concurrencia y articulación de normas laborales”, Revista de Política Social, Madrid, núm. 119, 1978, pp. 5 y ss.

67 Sobre las características del criterio jerárquico, y su aparente capacidad para resolver antinomias, véase Henríquez, Miriam, "Los jueces y la resolución de antinomias desde la perspectiva de las fuentes del derecho constitucional chileno", Estudios Constitucionales, Talca, año 11, núm.1, 2013, pp. 459 y ss. 
medida, también lo recoge el inciso segundo del artículo 1o. de dicho Código del Trabajo al disponer que las normas de ese Código no se aplican a los funcionarios de la administración del Estado "siempre que dichos funcionarios o trabajadores se encuentren sometidos por ley a un estatuto especial". Todas estas reglas son de usual aplicación en el ámbito laboral, aun cuando nada de ello impide, en todo caso, que las antinomias se mantengan pues no existe una solución mecánica de las mismas. ${ }^{68}$

Lo anterior no ocurre con los principios, ya que la eventual colisión se resuelve tomando en cuenta las circunstancias del caso, ponderando la importancia del supuesto analizado y estableciendo al efecto una precedencia condicionada. Y lo anterior se explica por el simple hecho de que los principios no establecen consecuencias precisas, sino que permiten enunciar motivos para decidir en un determinado sentido. ${ }^{69}$ Por ello, el principio de mayor peso prevalece. $^{70}$

En el caso del derecho del trabajo, las reglas o principios de aplicación propios de este ordenamiento (y que se han positivizado a partir de las exigencias tutelares de esta disciplina) no son de textura abierta. Por el contrario, los mentados principios de aplicación del derecho del trabajo no son más que reglas específicas, con supuestos de hecho cerrado (en el sentido que enumera exhaustivamente las circunstancias que "produce[n] la consecuencia jurídica que ella misma dispone"), ${ }^{71}$ y que han derivado en técnicas de ordenación y articulación del sistema de fuentes. ${ }^{72}$ Estas reglas, además, han terminado siendo mandatos imperativos o taxativos que permiten resolver específicos supuestos de hecho, pero que evitan la ponderación. ${ }^{73}$

68 Véase Ruiz, Juan, "Sistema jurídico: lagunas...”, cit., pp. 61 y 62. Si existe antinomia entre lex superior y lex posterior, debiera prevalecer el criterio jerárquico sobre el criterio cronológico. A la misma conclusión habría que arribar en caso de producirse una antinomia entre lex superior y lex specialis: "En tal situación, parece haber un acuerdo general en que hay una presunción prima facie a favor de lex superior". Con todo, si se produce una antinomia entre lex posterior y lex specialis, aquí no se produce una "presunción prima facie en favor de ninguna de las soluciones posibles, sino que cuál sea la solución para adoptar dependerá, sin más, del peso de los principios que respaldan a una y otra de las reglas antinómicas", ibidem, p. 63.

69 Pérez, Antonio-Enrique, "Los principios generales...", cit., p. 12.

70 Véase, Alexy, Robert, Teoría de los..., cit., pp. 71 y 73.

71 Guastini, Riccardo, Interpretary..., cit., p. 187.

72 Véase Mercader, Jesús, Los principios de..., cit., p. 31.

73 Atienza, Manuel, y Ruiz Manero, Juan, Las piezas del..., cit., p. 32. Y agregan: "Las reglas están destinadas, pues, a que, cuando se dan sus condiciones de aplicación, los órganos jurisdiccionales excluyan, en cuanto base de su resolución, su propio juicio acerca del balance de razones aplicables y adopten como tal base el contenido de la regla", ibidem, p. 35. 
Ante el derecho del trabajo, estas reglas obtuvieron patente de principio, aun cuando en no pocos casos sólo habían sido criterios de interpretación o postulados reconocidamente legales o estructurados a partir de la acción jurisprudencial. Un buen ejemplo de ello puede observarse en el denominado principio de irrenunciabilidad cuya formulación legal en muchos textos laborales sólo circunscribe y limita el ejercicio del derecho al disponer que la garantía de la prohibición de renuncia sólo es predicable de derechos legales (ya sean de imperatividad absoluta o derecho necesario relativo, ${ }^{74}$ pero no de derechos convencionales), establecidos en leyes laborales (no en cualquier norma jurídica), y sólo mientras se encuentre vigente el contrato de trabajo (es decir, se excluyen de la irrenunciabilidad los derechos adquiridos en los estadios previos a la contratación y los que ocurran con posterioridad a la extinción del vínculo). Desde esta perspectiva, la regla legal de la irrenunciabilidad exige que se haga exactamente lo que ella ordena y delimita el supuesto de hecho normativo, así como el efecto jurídico derivado de su concurrencia. ${ }^{75}$

Lo expuesto permite reafirmar una y otra vez que el principio de protección del trabajador constituye el gran principio de esta disciplina y que, a partir de allí, se deducen derivaciones y especificaciones mediante reglas tanto del orden sustantivo como procesal. Lo anterior no obsta a reconocer que, en el derecho del trabajo, en tanto rama del ordenamiento jurídico, también se aplican los principios generales del derecho, los cuales son comunes a todo el sistema jurídico. Sería totalmente contradictorio, desde el punto de vista de la unidad del sistema jurídico, pretender una separación absoluta entre principios generales y principios laborales. ${ }^{76}$ Pero esos principios generales no son

74 Camps, Luis Miguel, "El carácter mínimo de las normas laborales", Cuadernos de Derecho del Trabajo, Valencia, núms. 1 y 2, 1975-1976, pp. 4 y ss.; Prados, Francisco Javier, "Renuncia y transacción de derechos en el Estatuto de los Trabajadores", Revista de Política Social, Madrid, núm. 127, 1980, pp. 55 y ss.; Villa, Luis Enrique de la, "El principio de la irrenunciabilidad de los derechos laborales", Revista de Política Social, Madrid, núm. 85, 1970, pp. 7 y ss.

75 Cruz, Jesús, “Los principios...”, cit., p. 199.

76 Véase Vida José et al., Manual de derecho..., cit., p. 38: "Se debe dejar constancia que, desde un punto de vista estrictamente jurídico, que en derecho del trabajo no hay más principios, que los "principios generales del derecho», de los que no se puede por menos de participar el derecho del trabajo si es que se quiere seguir denominando «derecho»"; Lyon-Caen, Gérard, "Les príncipes généraux...", cit., p. 36; Jeammaud, Antoine, "Les príncipes...", cit., pp. 622 y ss.; Montoya, Alfredo, "La aplicación...”, cit., p. 28; Mercader, Jesús, Los principios de..., cit., p. 55; Cruz, Jesús, ibidem, p. 205; Irureta, Pedro, "El impacto de los...”, cit., p. 304; Almansa, J. M., "Los principios generales del derecho en las fuentes normativas del derecho del trabajo", Cuadernos de la Cátedra de Derecho del Trabajo, núm. 3, Valencia, 1972, p. 13; Vázquez, Antonio, Tratado de derecho..., cit., p. 126; Deveali, Mario L., Tratado de..., cit., p. 386. 
reglas jurídicas específicas, cuestión que obliga a concluir que el ordenamiento laboral es una amalgama de técnicas y principios peculiares que conviven con técnicas y principios ya existentes en otras ramas jurídicas. ${ }^{77}$

\section{CONCLUSIONES}

$\mathrm{E}$ 1 derecho del trabajo, como disciplina jurídica, está conformado por principios y reglas. Para efectos de la disciplina laboral, el único y gran principio es el denominado principio protector. Éste ha estado en la base fundacional de la regulación jurídica del trabajo, y a partir de él, se han desplegado diversos tipos de reglas que reafirman el postulado tutelar.

Lo que tradicionalmente se denomina principios clásicos del derecho del trabajo, no son más que reglas establecidas bajo la lógica del todo o nada. Dentro de esas reglas podemos identificar, entre otras, a figuras tan clásicas como la irrenunciabilidad, la continuidad laboral o la primacía de la realidad. Todas esas reglas derivan de un solo gran principio fundante de la disciplina, como lo es el principio protector.

En el orden laboral, doctrina y jurisprudencia han obviado la distinción entre principios y reglas, limitándose a efectuar un tratamiento unitario de ambas figuras bajo la lógica que todos estos postulados constituyen principios propios del orden laboral. Sin embargo, no son lo mismo. El principio protector se estructura como un mandato de optimización que ordena que algo sea realizado en la mayor medida de lo posible. Por el contrario, las reglas (dentro de las cuales destacan la irrenunciabilidad, la continuidad laboral o la primacía de la realidad) son normas con un menor nivel de generalidad y que sólo permiten hacer aquello que exactamente se exige. Los llamados principios de aplicación del derecho del trabajo no son más que reglas específicas con supuestos de hecho cerrados y que evitan la ponderación. En caso de producirse conflicto entre reglas, la jurisprudencia laboral utiliza las antinomias dentro de las cuales se impone la mayor parte de las veces el criterio jerárquico y la regla de especialidad (lex specialis derogat generali).

La existencia en exclusiva del principio protector - y de sus reglas particulares - no evita que en el derecho del trabajo se apliquen además los principios generales del derecho. Si el orden laboral aspira a ser una disciplina

77 Véase Monereo, J. L., Algunas reflexiones sobre la caracterización técnico-juridica del derecho del trabajo, Madrid, Civitas, 1996, p. 45. 
propiamente jurídica, integrante de un sistema mayor, en modo alguno puede pretender negarle cabida a estos principios generales. Lo anterior permite concluir que el ordenamiento laboral es una combinación de reglas, técnicas y principios particulares que conviven con técnicas, reglas y principios aplicables a todo el sistema jurídico.

\section{BIBLIOGRAFÍA}

AARNIO, Aulis, "Reglas y principios en el razonamiento jurídico", Anuario da Facultade de Dereito da Universidade da Coruña, La Coruña, núm. 4, 2000.

ACKerman, Mario, "El principio protectorio o de protección", en PASCO, Mario (coord.), En torno a los principios del derecho del trabajo. Homenaje al Dr. Américo Plá Rodríguez, México, Porrúa, 2005.

Aguiló, Josep, Teoría de las fuentes del derecho (y el orden jurídico), Barcelona, Ariel, 2012.

AlARCÓN, Manuel Ramón, "La vigencia del principio pro operario", en MONTOYA, A. et al. (coord.), Cuestiones actuales de derecho del trabajo. Estudios ofrecidos por los catedráticos españoles de derecho del trabajo al profesor Manuel Alonso Olea, Madrid, Centro de Publicaciones, Ministerio de Trabajo y Seguridad Social, 1990.

ALEXY, Robert, Teoría de los derechos fundamentales, trad. de Carlos Bernal Pulido, Madrid, Centro de Estudios Políticos y Constitucionales, 2017.

Almansa, José Manuel, "Los principios generales del derecho en las fuentes normativas del derecho del trabajo", Cuadernos de la Cátedra de Derecho del Trabajo, Valencia, núm. 3, 1972.

Almansa, José Manuel, "Los principios generales del derecho ante la jurisprudencia constitucional laboral”, en IGLESIA, J. L. (coord.), Estudios jurídicos en homenaje al profesor Aurelio Menéndez, Madrid, Civitas, 1996, t. IV.

ARCE Y FLORES-VALDÉS, Joaquín, Los principios generales del derecho y la formulación constitucional, Madrid, Civitas, 1990.

ATIENZA, Manuel y RuIZ, Juan, "Sobre principios y reglas", Doxa, Valencia, núm. 10, 1991.

AtienZA, Manuel y Ruiz, Juan, Las piezas del derecho, 4a. ed., Barcelona, Ariel, 2016. 
Barbagelata, Héctor-Hugo, "Los principios de derecho del trabajo de segunda generación”, IUSlabor, núm. 1, 2008.

BÄCKER, Carsten, "Reglas, principio y derrotabilidad", trad. de Francisco J. Campos Zamora, Doxa, Valencia, núm. 37, 2014.

BArros, Enrique, "Reglas y principios en el derecho", Anuario de Filosofía Jurídica y Social, Santiago, núm. 2, 1984.

BECCHI, Paolo, El principio de la dignidad humana, México, Fontamara, 2016.

BELADÍEZ, Margarita, Los principios jurídicos, 2a. ed., Madrid, Civitas, 2010.

BocQuillon, Fabrice, "Que reste-t-il du 'principe de faveur'?", Droit Social, París, núm. 3, 2001.

BONNECHÈRE, Michèle, "Sur l'ordre public en droit du travail: les príncipes sont toujourd là...", Le Droit Ouvrier, París, núm. 714, 2008.

CAAMAÑO, Eduardo, "Análisis crítico sobre la aplicación de la doctrina de los actos propios en materia laboral", Revista de Derecho de la Pontificia Universidad Católica de Valparaíso, Valparaíso, núm. 32, 2009.

CAMPS, Luis Miguel, "El carácter mínimo de las normas laborales", Cuadernos de Derecho del Trabajo, Valencia, núms. 1 y 2, 1975-1976.

CONDE, Emilia, La buena fe en el contrato de trabajo, Madrid, La Ley, 2007.

CRUZ, Jesús, "Los principios informadores del ordenamiento laboral", en FARGAS, J., (coord.), Los derechos laborales desde la perspectiva de la teoría general del contrato y de la normativa internacional, Barcelona, Huygens, 2016.

CRUZ, Jesús, "La investigación en el derecho del trabajo", Lineamientos metodológicos para la investigación jurídica, Lima, núm. 2, 2016.

CRuZ, Jesús, Compendio de derecho del trabajo, 11a. ed., Madrid, Tecnos, 2018.

CHANDíA, Sebastián, "Principios jurídicos y ordenamiento jurídico. Bases para una teoría general de los principios jurídicos en el sistema constitucional chileno", Derecho y Humanidades, Santiago, núm. 20, 2012.

DesDentado, Aurelio, "El principio pro operario", en VilLA, Luis Enrique de la, y López Cumbre, L. (dirs.), Los principios del derecho del trabajo, Madrid, Centro de Estudios Financieros, 2003.

Deveali, Mario, Tratado de derecho del trabajo, Buenos Aires, La Ley, 1964, t. I.

DwOrkin, Ronald, Los derechos en serio, trad. de Martha Gustavino, Barcelona, Ariel, 1999.

ESSER, Jossef, Principio y norma en la elaboración jurisprudencial del derecho privado, Barcelona, Bosch, 1961. 
GAETE, Alfredo, Principios generales de derecho del trabajo, Santiago, Editorial Jurídica de Chile, 1951.

GÁRATE, Javier, "El principio in dubio pro operario", Revista de Política Social, Madrid, núm. 135, 1982.

GonZÁLEZ Del ReY, Ignacio, "Principios generales”, en GARCíA, J. (ed.), El sistema de fuentes de la relación laboral: estudios ofrecidos al profesor Martín Valverde por el Área de Derecho del Trabajo de la Universidad de Oviedo, Oviedo, Ediciones de la Universidad de Oviedo, 2007.

GonZÁLEZ, Jesús, La dignidad de la persona, 3a. ed., Pamplona, Civitas-Thomson Reuters, 2017.

GUASTINI, Riccardo, Interpretary argumentar, trad. de Silvina Álvarez Medina, Madrid, Centro de Estudios Políticos y Constitucionales, 2014.

GuASTINI, Riccardo, Las fuentes del derecho. Fundamentos teóricos, trad. de César E. Moreno More, Lima, Legales Ediciones, 2017.

GuZMÁN, Alejandro, "La idea de «principio» mentada en la expresión «principios generales del derecho»", en REINOSO, F. (dir.), Principios generales del derecho. Antecedentes históricos y horizonte actual, Madrid, Thomson ReutersAranzadi, 2014.

Henríquez, Miriam, "Los jueces y la resolución de antinomias desde la perspectiva de las fuentes del derecho constitucional chileno", Estudios Constitucionales, Talca, año 11, núm. 1, 2013.

HeREDIA, Ignasi, La estabilidad en el empleo: un concepto al margen de la duración temporal o indefinida del contrato, Pamplona, Aranzadi-Thomson Reuters, 2011.

Hoerster, Norbert, En defensa del positivismo jurídico, trad. de Ernesto Garzón Valdés, Barcelona, Gedisa, 2000.

IRURETA, Pedro, "Constitución y orden público laboral: un análisis del art. 19 No. 16 de la Constitución chilena", Colección de Investigaciones Jurídicas, núm. 9, Santiago, Facultad de Derecho de la Universidad Alberto Hurtado, 2006.

IRURETA, Pedro, "El impacto de los principios jurídicos en el derecho del trabajo", en CARBOnelL, F. et al. (coords.), Principios jurídicos. Análisis y crítica, Santiago, Legal Publishing, 2011.

IRURETA, Pedro, "La vigencia del principio de buena fe en el derecho del trabajo chileno", Ius et Praxis, Talca, año 17, núm. 2, 2011. 
JEAmmaud, Antoine, "Les príncipes dans le droit francais du travail", Droit Social, París, núms. 9-10, 1982.

JEAmMAUD, Antoine, "Le príncipe de faveur. Enquête sur une règle emergente”, Droit Social, París, núm. 2, 1999.

JeAmmaud, Antoine, "L'inexistence, en droit du travail, d'un príncipe pro operario", en CRUZ, J. et al. (coords.), Los grandes debates actuales en el derecho del trabajo y la protección social. Estudios en recuerdo del profesor Dr. Manuel Ramón Alarcón Caracuel, Sevilla, Centro Andaluz de Relaciones Laborales, 2016.

JaviLLIER, Jean-Claude, Derecho del trabajo, Montevideo, Fundación de Cultura Universitaria, 2007.

LASTRA, José Manuel, "Principios ordenadores de las relaciones de trabajo", Revista Española de Derecho del Trabajo, Madrid, núm. 104, 2001.

LEGuinA, Jesús, “Principios generales del derecho y Constitución”, Revista de Administración Pública, Madrid, núm. 114, 1987.

LÓPEZ ONETO, Marcos, El principio de protección a la fuente del empleo en Chile, Santiago, Thomson Reuters, 2013.

LuZZATI, Claudio, El principio de autoridady la autoridad de los principios, trad de Pau Luque Sánchez, Madrid, Marcial Pons, 2013.

LyON-CAEN, Gérard, "Les príncipes généraux du droit du travail", Téndances du droit du travail français contemporain. Études offertes à $G$. H. Camerlynck, París, Dalloz, 1978.

MARTín, Antonio, "Principios y reglas en el derecho del trabajo. Planteamiento teórico y algunos ejemplos", en DE LA VILLA GIL, L. E. y LÓPEZ, L. (dirs.), Los principios del derecho del trabajo, Madrid, Centro de Estudios Financieros, 2003.

MARTín, Antonio, “Concurrencia y articulación de normas laborales", Revista de Política Social, Madrid, núm. 119, 1978.

MArTín, Antonio et al., Derecho del trabajo, 24a. ed., Madrid, Tecnos, 2015.

MerCADER, Jesús, Los principios de aplicación del derecho del trabajo, Valencia, Tirant lo Blanch, 2014.

MONEREO, José Luis, Algunas reflexiones sobre la caracterización técnico jurídica del derecho del trabajo, Madrid, Civitas, 1996.

Montoya, Alfredo, "Principios y valores en el derecho del trabajo", en PASCO, Mario (coord.), En torno a los principios del derecho del trabajo. Homenaje al Dr. Américo Plá Rodríguez, México, Porrúa, 2005. 
Montoya, Alfredo, Derecho del trabajo, 29a. ed., Madrid, Tecnos, 2008.

MonTOYA, Alfredo, "La aplicación del derecho del trabajo y el sistema de principios, valores y derechos fundamentales", Revista del Ministerio de Trabajo e Inmigración, Madrid, núm. 88, 2010.

PACHECO, Luz, La dignidad bumana en el derecho del trabajo, Madrid, ThomsonCivitas, 2007.

Palavecino, Claudio, Los principios del derecho del trabajo, Santiago, Facultad de Derecho de la Universidad de Chile, Separata, 2008.

Palomo, Rodrigo, "Los principios del derecho del trabajo. Cuestiones de la teoría tradicional y planteamiento de nuevos problemas", Revista Laboral Chilena, Santiago, núm. 6, 2006.

PAlomo, Rodrigo, "El rol de los principios en la aplicación del derecho del trabajo. Antecedentes conceptuales sobre el estado del arte en Chile", Revista Laboral Chilena, Santiago, núm 11, 2007.

PLÁ, Américo, Los principios del derecho del trabajo, Buenos Aires, Ediciones Depalma, 1978.

PLÁ, Américo, "Los principios del derecho del trabajo ¿constituyen una fuente del derecho?", Treinta y seis estudios sobre las fuentes del derecho del trabajo, Montevideo, Fundación de Cultura Universitaria, 1995.

PÉREZ, Antonio-Enrique, "Los principios generales del derecho: ¿un mito jurídico?”, Revista de Estudios Políticos, Madrid, núm. 98, 1997.

PodetTi, H., "Los principios del derecho del trabajo", en DE BUEN, N. y Morgado, E. (coords.), Instituciones de derecho del trabajo y de la seguridad social, México, Academia Iberoamericana de Derecho del Trabajo-UNAM, 1997.

PRADOS, Francisco Javier, "Renuncia y transacción de derechos en el Estatuto de los Trabajadores", Revista de Política Social, Madrid, núm. 127, 1980.

PRIETO, Luis, Ley, principios, derechos, Madrid, Dykinson, 1998.

Prieto, Luis, Apuntes de teoría del derecho, 10a. ed., Madrid, Trotta, 2016.

RAMos, José Antonio, "El fundamento del valor jurídico de los principios. Dworkin frente a Esser", Anuario de Filosofía del Derecho, Madrid, t. IX, 1992.

RoDríguez, Jesús, "Los principios del derecho del trabajo", en GARCíA, H. et al. (dirs.), El derecho del trabajo en tiempos de cambio. En honor de Adrián Goldin, Buenos Aires, Ediar, 2017. 
RODRÍGUEZ, Jesús, "Realismo y principios jurídicos en el derecho del trabajo”, Derecho del Trabajo, Buenos Aires, año XLVIII, núm. 11, 1988.

RODRÍGUEZ-PIÑERO, Miguel, "Flexibilidad, juridificación y desregulación”, Relaciones Laborales, Madrid, 1987, t. I.

RojAs, Víctor Manuel, Dworkin y los principios generales del derecho, México, Porrúa, 2007.

RUIZ, Juan, "Sistema jurídico: lagunas y antinomias", en GonZÁLEZ, D. (coord.), Conceptos básicos del derecho, Madrid, Marcial Pons, 2015.

SAgARDOY, Juan Antonio, Los principios de aplicación del derecho del trabajo, 2a. ed., Madrid, Acarl, 1991.

TARDíO, J. A., Los principios generales del derecho, Barcelona, Bosch, 2011.

THAYER, William, "Un punto de vista sobre los principios del derecho del trabajo", Revista Jurídica del Trabajo, Santiago, núm. 501, 1984.

THAYER, William y NovOA, Patricio, Manual de derecho del trabajo, 3a. ed., Santiago, Editorial Jurídica de Chile, 1998, t. II.

UGARTE, José Luis, "La rehabilitación de los principios del derecho del trabajo y el concepto del derecho", Derecho Laboral, Montevideo, núm. 252, 2013.

VARIOS AUTORES, Los principios del derecho del trabajo en el derecho peruano. Libro homenaje al profesor Américo Plá Rodríguez, Lima, Grijley, 2009.

VARIOS AUTORES, En torno a los principios del derecho del trabajo, en PASCO COSMÓPOLIS, Mario (coord.), México, Porrúa, 2009.

VÁzQuez, Antonio, Tratado de derecho del trabajo, Buenos Aires, Astrea, 1993, t. 2 .

VIDA, José et al., Manual de derecho del trabajo, 3a. ed., Granada, Comares, 2005.

VILLA, Luis Enrique de la, "El principio de la irrenunciabilidad de los derechos laborales", Revista de Política Social, Madrid, núm. 85, 1970.

VILLA, Luis Enrique de la, "Rasgos, caracteres y principios del derecho del trabajo”, en PAlomeque, M. C. y GArCía-Perrote, I. (coords.), Derecho del trabajo y seguridad social: cincuenta estudios del profesor Luis Enrique De la Villa Gil: Homenaje a sus 50 años de dedicación universitaria, Madrid, Centro de Estudios Financieros, 2006.

VILLA, Luis Enrique de la, "El principio de adecuación social y los conceptos jurídicos indeterminados en el derecho del trabajo", en PALOMEQUE, M. C. y GARCíA-PERrote, I. (coords.), Derecho del trabajo y seguridad social: cin- 
cuenta estudios del profesor Luis Enrique De la Villa Gil: Homenaje a sus 50 años de dedicación universitaria, Madrid, Centro de Estudios Financieros, 2006.

WALKER, Francisco, "Algunas reflexiones de carácter doctrinario sobre los embates flexibilizadores de las relaciones laborales, los principios del derecho del trabajo, su razón de ser y su futuro", Temas Laborales, Santiago, año 7, 2002.

WALKer, Francisco, "Principios orientadores del derecho del trabajo", Revista Jurídica del Trabajo, Santiago, núm. 501, 1984. 